\title{
Bacterial Cellulose Production by Acetobacter xylinum CGMCC 1.2378 Using Coconut Shell Acid Hydrolysate as Carbon Source
}

\author{
Yu Liu, Fangfang Wang, and Yangyang Sun *
}

\begin{abstract}
Bacterial cellulose (BC) was synthesized by Acetobacter xylinum using a carbon source of coconut shell hydrolysate, which was treated with an ultra-low concentration of sulfuric acid. The coconut shell was found to contain $57.13 \%$ holocellulose and $27.42 \%$ lignin. The effect of sulfuric acid concentration, reaction temperature, and reaction time on hydrolysis of coconut shell were evaluated by response surface methodology. The reducing sugar concentration was $8.39 \mathrm{~g} / \mathrm{L}$ under the predicted optimum treatment at $200{ }^{\circ} \mathrm{C}$ for 32 min with a solution of $0.07 \%$ sulfuric acid. The holocellulose conversion rate was $56.1 \%$ at this condition. In a detoxification process using calcium hydroxide and activated carbon, furfural and hydroxymethylfurfural in the hydrolysate were almost completely removed, whereas formic acid and acetic acid levels decreased by $30 \%$. After cultivation for 7 days at the reducing sugar status of $5 \mathrm{~g} / \mathrm{L}$, the $\mathrm{BC}$ production in medium with the detoxified hydrolysate could reach $1.66 \mathrm{~g} / \mathrm{L}$. After fermentation for 21 days, BC yield in medium using composited carbon source $(20 \mathrm{~g} / \mathrm{L})$ of glucose and hydrolysate was 5.30 $\mathrm{g} / \mathrm{L}$. Structural analysis showed that BC obtained from medium of control and detoxified hydrolysate exhibited similar properties. This work provided a potential method for $\mathrm{BC}$ production.
\end{abstract}

Keywords: Bacterial cellulose; Acetobacter xylinum; Coconut shell; Hydrolysate

Contact information: State Key Laboratory of Biobased Material and Green Papermaking, Qilu University of Technology, Shandong Academy of Sciences, Jinan, Shandong Province, P. R. China, 250353;

* Corresponding author: syyibcas@126.com

\section{INTRODUCTION}

Cellulose is a polymer of glucose units linked together by $\beta$-1,4-glycosidic bonds and is one of the most abundant natural polymers on earth (Hong and Qiu 2008; Ruan et al. 2016; Ye et al. 2019). Bacterial cellulose (BC), which has similar chemical composition to plant cellulose, has received ample attention since its discovery in 1886 (Campano et al. 2015; Cheng et al. 2017). The fine and well-ordered structure of BC offers great properties such as high degrees of purity, high tensile strength, water-holding capacity, biodegradability, and biological adaptability (Esa et al. 2014; Wang et al. 2019). Due to these remarkable characteristics, BC has been widely used in the textile, food, and biomedical industries (Gallegos et al. 2016; Lin et al. 2020; Wang et al. 2019).

Various bacteria produce cellulose, such as Gluconacetobacter xylinum, Rhizobium, Azotobacter, and Agrobacterium (Shoda and Sugano 2005; Esa et al. 2014; Kucińska-Lipka et al. 2015). Among them, Gluconacetobacter xylinus (also known as Acetobacter xylinus) is the most studied and the most efficient BC producer, with good adaptability to variable substrates (El-Saied et al. 2004). The typical substrate for BC

Liu et al. (2021). "Bacterial cellulose from coconut shell," BioResources 16(1), 1042-1062. 1042 
production includes several types of carbon sources, such as glucose, sucrose, fructose, glycerol, and mannitol (Mohammadkazemi et al. 2015). The fermentation medium costs almost $30 \%$ of $\mathrm{BC}$ production, which has partly prevented widescale use of $\mathrm{BC}$ for industrial production (Rivas et al. 2004). Therefore, the exploration of new cost-effective carbon sources with shorter fermentation times for high yield BC production is necessary.

Various agroforestry residues and industrial by-products have been utilized as beneficial carbon sources in BC production, such as corn stalks (Cheng et al. 2017), corncob acid hydrolysate (Huang et al. 2015), distillery effluent (Jahan et al. 2018), fruit juice (Kim et al. 2017), and waste beer yeast (Lin et al. 2014). The production of BC by biomass hydrolysate is a current research focus. Biomass resources containing cellulose and hemicellulose are hydrolyzed to reducing sugar, which could be used as a carbon source in BC fermentation. There are several methods to hydrolyze lignocellulose material (Menon and Rao 2012). The ultra-low concentration sulfuric acid method has the advantages of low corrosion to equipment, low cost in $\mathrm{pH}$ regulation, and simplicity (Kim et al. 2001). More importantly, because of the low concentration of sulfate ions and inorganic salts, the hydrolysate treated with ultra-low acid concentration is more suitable for microbial growth. For these reasons, the ultra-low concentration sulfuric acid method was explored in this study.

Coconut shell is a natural biomass with abundant reserves and low price. It is produced in Hainan province of China and several tropical countries. The material varies greatly in color and composition between different regions. Coconut shell is widely used in soilless culture because of its good water retention and air permeability. This material is suitable for hemicellulose extraction and xylose generation (Liu et al. 2006; Wang et al. 2017). Moreover, coconut shell has been explored as a coarse aggregate in concrete (Kanojia and Jain 2017; Palanisamy et al. 2020). However, there are no reports showing coconut shell as a carbon source for BC production.

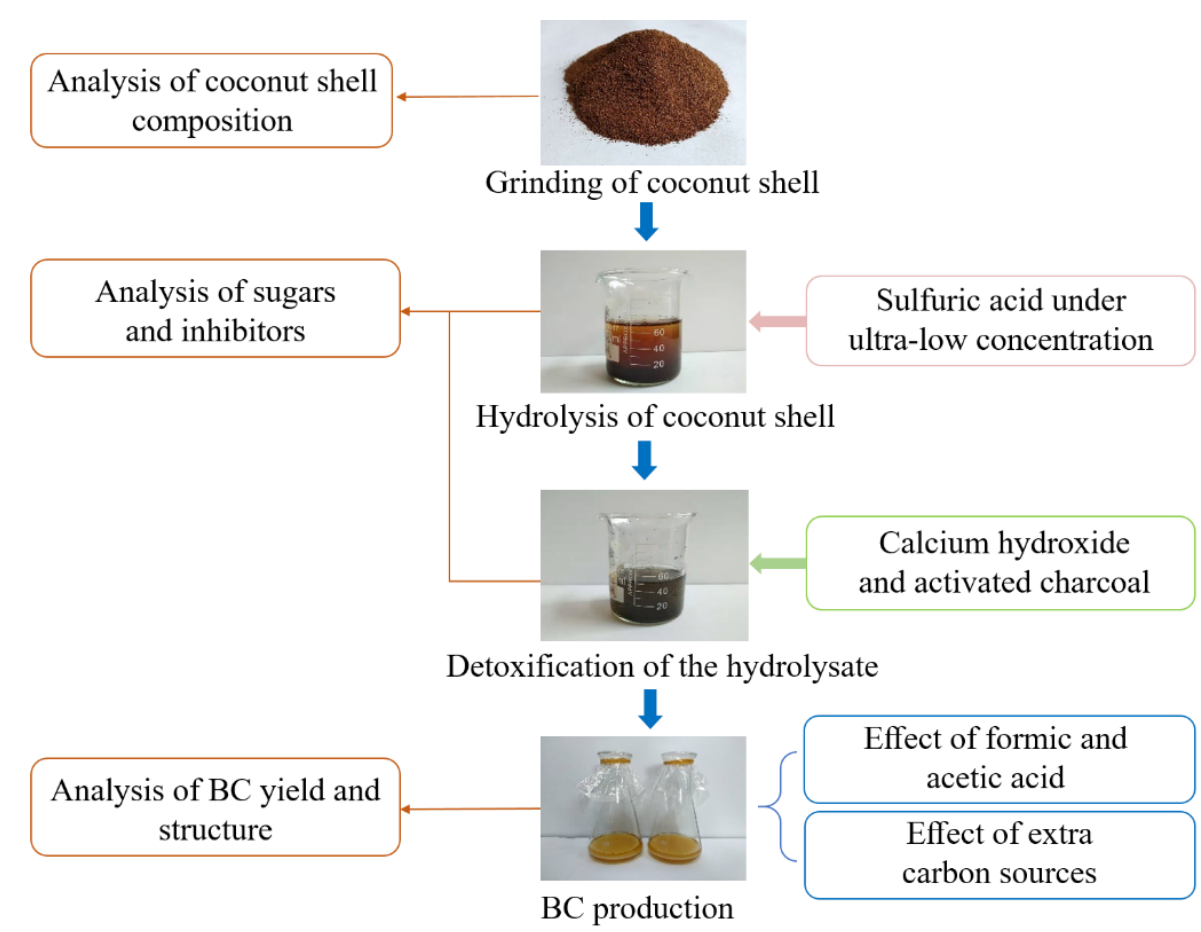

Fig. 1. Flow chart of the experiment 
To develop a sustainable and alternative method for BC production from coconut shell, this study analyzed the components of coconut shell and then explored the efficient method of hydrolyzing the material with an ultra-low content of sulfuric acid (Fig. 1). After removing microbial growth inhibitors, the hydrolysate was evaluated as a carbon source for $\mathrm{BC}$ production. The project provides a feasible way to utilize coconut shell in $\mathrm{BC}$ production.

\section{EXPERIMENTAL}

\section{Materials}

Coconut chaff was collected from Hainan Province, China (Yuan Run Ecological Agriculture Co., Ltd. (Jinan, China). Acetobacter xylinum CGMCC 1.2378 was purchased from China General Microbiological Culture Collection Center, Institute of Microbiology, Chinese Academy of Sciences (Beijing, China). Activated charcoal (product No.GH 13) was obtained from Beijing Brilliant Technology Co., Ltd. (Beijing, China). Other chemicals used for standard in this study were purchased from Beijing Solarbio Science \& Technology Co., Ltd. (Beijing, China).

\section{Coconut Shell Composition Analysis}

To examine the potential of the coconut chaff as carbon source, its main components including water content, ash, holocellulose, and lignin of the material were analyzed by conventional methods. First, $50 \mathrm{~g}$ of the ground material was dried overnight at $105^{\circ} \mathrm{C}$ to a constant weight for calculating the water content and then maintained in a desiccator. To determine the ash concentration, samples were carbonized and then burned at $575{ }^{\circ} \mathrm{C}$ for $30 \mathrm{~min}$, followed by weighing the residue. The holocellulose content was assayed according to the National standards of the People's Republic of China (GB/T 2677.10 1995). The contents of acid-insoluble lignin and acid-soluble lignin in the raw material were explored on the basis of GB/T 2677.8 (1994) and GB/T 10337 (2008).

\section{Hydrolysis of Coconut Chaff}

Previous studies indicated that acid concentration $\left(X_{1}\right)$, reaction temperature $\left(X_{2}\right)$, and the reaction time $\left(X_{3}\right)$ had obvious effects on hydrolysis of lignocellulose material $(\mathrm{Ge}$ et al. 2011, Kim et al. 2001; Xiang et al. 2003). In preliminary experiments, the reasonable experimental range and levels for these independent variables in hydrolyzing coconut shell under ultra-low concentration of sulfuric acid was explored. The material was ground and treated by $75 \mathrm{~mL}$ sulfuric acid of $0.05 \%$ mass fraction for 10, 20,30, or $40 \mathrm{~min}$ at 170, 190, or $210^{\circ} \mathrm{C}$. A high-pressure agitated autoclave was used in this assay. Because of the light weight and high water absorption capacity of the material, a low mass-to-volume ratio (1:25) was used. The hydrolysate was collected by filtration for determination of monosaccharides and fermentation inhibitors. The solid residue was dried at $80{ }^{\circ} \mathrm{C}$ for analysis of holocellulose in study of holocellulose conversion to reducing sugar.

Thereafter, the response surface methodology (RSM) was used for optimization analysis of hydrolysis. Design Expert 8.0.6 software has been used for the design, mathematical modeling, statistical analysis, and optimization of the variables (Wang et al. 2018; Zhang et al. 2020). The reaction conditions were optimized by the Box-Behnken 
design (BBD) in the software. Table 1 shows the experimental range and levels for the independent variables.

Table 1. Experimental Range and Levels for the Independent Variables

\begin{tabular}{|l|l|l|l|l|l|}
\hline $\begin{array}{l}\text { Independent } \\
\text { valuables }\end{array}$ & Unit & Symbol & Level 1 & Level 2 & Level 3 \\
\cline { 4 - 6 } & & & Low, $(-1)$ & Mid, (0) & High, (1) \\
\hline Acid concentration & $\%$ (mass fraction) & $X_{1}$ & 0.02 & 0.06 & 0.10 \\
\hline Temperature & ${ }^{\circ} \mathrm{C}$ & $X_{2}$ & 180 & 200 & 220 \\
\hline Time & min & $X_{3}$ & 25 & 35 & 45 \\
\hline
\end{tabular}

Based on the analysis of variance (ANOVA) table, the regression equation was generated to predict the optimal value of the RSC in the hydrolysate. Equal (1) represents the regression equation,

$\mathrm{RSC}=\alpha_{0}+\alpha_{1} X_{1}+\alpha_{2} X_{2}+\alpha_{3} X_{3}+\alpha_{11} X_{1}^{2}+\alpha_{22} X_{2}^{2}+\alpha_{33} X_{3}^{2}+\alpha_{12} X_{1} X_{2}+\alpha_{13} X_{1} X_{3}+\alpha_{23} X_{2} X_{3}(1)$

where $X_{1}, X_{2}$, and $X_{3}$ are the independent variables; $\alpha_{0}$ represents the intercept value at the zero levels of the $X$ terms; $\alpha_{1}, \alpha_{2}$, and $\alpha_{3}$ are the linear coefficients; $\alpha_{11}, \alpha_{22}$, and $\alpha_{33}$ are quadratic coefficients; $\alpha_{12}, \alpha_{13}$, and $\alpha_{23}$ are the interaction coefficients. Besides, mean squares, sum of squares, the degree of freedom (DoF), F-value, and P-value are parameters to check the efficacy of the model.

\section{Detoxification Treatment}

The material was treated with $75 \mathrm{~mL}$ sulfuric acid of $0.05 \%$ mass fraction for 20 min, with temperature of $210^{\circ} \mathrm{C}$. In the assay of detoxification of the hydrolysate, the $\mathrm{pH}$ value of the samples was adjusted to 10.0 by calcium hydroxide $\left[\mathrm{Ca}(\mathrm{OH})_{2}\right]$. After incubating at $30{ }^{\circ} \mathrm{C}$ for $12 \mathrm{~h}$ (Hong et al. 2011), the $\mathrm{pH}$ of the solution was adjusted to 5.0, 6.0 , or 7.0 with $0.1 \mathrm{~mol} / \mathrm{L} \mathrm{H}_{2} \mathrm{SO}_{4}$. After adding a certain dosage $(1,2,3$, or $4 \mathrm{~g} / \mathrm{L})$ of activated charcoal into the hydrolysate, the mixture was shaken at $200 \mathrm{rpm}$ and $60{ }^{\circ} \mathrm{C}$ for $3 \mathrm{~h}$, followed by filtration.

\section{Sugar and Microbial Growth Inhibitors Analysis}

The contents of sugars and microbial grow inhibitors in the hydrolysate were assayed after sulfuric acid treatment and detoxification. Glucose, arabinose, galactose, xylose, and mannose concentrations were evaluated via ion chromatography using an ICS5000 (Thermo Scientific, Waltham, MA, USA) equipped with a Dionex CarboPac ${ }^{\mathrm{TM}}$ PA20 ( $3 \times 150 \mathrm{~mm}$; Sunnyvale, CA, USA) separation column and a Dionex CarboPac PA20 (3 $\times 30 \mathrm{~mm}$ ) guard column. The $250 \mathrm{mmol} / \mathrm{L} \mathrm{NaOH}$ and distilled water (the volume ratio of two mobile phases is $1: 24$ ) were used for leaching at an equal rate of $0.4 \mathrm{~mL} / \mathrm{min}$. The RSC of the hydrolysate was determined using the 3, 5-dinitrosalicylic acid (DNS) method (Miller 1959). Glucose was used as the standard. The conversion rate of holocellulose to reducing sugar was calculated as follows,

$$
\alpha_{\mathrm{H}}=\left(m_{\mathrm{C}}-m_{\mathrm{R}}\right) / m_{\mathrm{C}} \times 100 \%
$$

where $\alpha_{\mathrm{H}}$ is the conversion rate of holocellulose to reducing sugar in coconut shell, $m_{\mathrm{C}}$ is the dry weight of holocellulose in raw materials $(\mathrm{g})$, and $m_{\mathrm{R}}$ is the quantity of holocellulose in the residue of hydrolysis after drying $(\mathrm{g})$.

The concentrations of microbial growth inhibitors [formic acid, acetic acid, furfural 
and 5-hydroxymethylfurfural (5-HMF)] were analyzed by high-performance liquid chromatography (Focus, Thermo Scientific) with an ion exchange chromatography column (HPX-87H, Bio-Rad, Hercules, CA, USA). The mobile phase contained phosphoric acid of $0.1 \%$ mass fraction and was delivered at a flow rate of $0.7 \mathrm{~mL} / \mathrm{min}$. All tests were performed in triplicate.

\section{BC Production and Harvest}

A. xylinum CGMCC 1.2378 strain was activated in culture medium containing 10.0 $\mathrm{g} / \mathrm{L}$ glucose, $10.0 \mathrm{~g} / \mathrm{L}$ peptone, and $5.0 \mathrm{~g} / \mathrm{L}$ yeast extract, with an initial $\mathrm{pH}$ of 6.5 . After incubating for 2 days at $30{ }^{\circ} \mathrm{C}$ with $150 \mathrm{rpm}$ shaking, the seed culture was inoculated into $50 \mathrm{~mL}$ liquid control or test medium of $5 \%$ inoculation proportion $(\mathrm{v} / \mathrm{v})$, followed by cultivating statically at $30{ }^{\circ} \mathrm{C}$ for 7 days. Whenever mentioned in this study, the control medium was at status of $5.0 \mathrm{~g} / \mathrm{L}$ glucose, $5.0 \mathrm{~g} / \mathrm{L}$ peptone, and $5.0 \mathrm{~g} / \mathrm{L}$ yeast extract, $\mathrm{pH}$ of 6.5. The text substrate used for BC production consisted of $5.0 \mathrm{~g} / \mathrm{L}$ peptone, $5.0 \mathrm{~g} / \mathrm{L}$ yeast extract and coconut shell hydrolysate (after detoxification or not) as sole carbon source, in which the RSC was diluted to $5.0 \mathrm{~g} / \mathrm{L}$. The purpose of hydrolysate dilution is to reduce the influence of fermentation inhibitors on BC production, as well as easer to compare with the control condition.

To investigate the effect of extra carbon sources on $\mathrm{BC}$ production, modified media was prepared by adding $5 \mathrm{~g} / \mathrm{L}$ glucose, fructose, sucrose, or mannose to medium using detoxified hydrolysate of coconut shell. In the assay with formic acid and acetic acid, both were added in the control medium at concentrations of $0.1,0.5,1.0,1.5,2.0$, and $2.5 \mathrm{~g} / \mathrm{L}$. The $\mathrm{pH}$ was adjusted to 6.5 with $0.1 \mathrm{~mol} / \mathrm{L} \mathrm{NaOH}$. In the assay of $\mathrm{BC}$ fermentation for 21 days, glucose was added to the detoxified hydrolysate to bring the final carbon source concentration to $20 \mathrm{~g} / \mathrm{L}$. Medium with $20 \mathrm{~g} / \mathrm{L}$ glucose was used as contrast. After 3, 7, 10, 14,17 , and 21 days of fermentation, the cellulose pellicles were harvested. The $\mathrm{pH}$ of the fermented liquid was adjusted to 6.5 after 7 and 14-day fermentation. Each culture was performed in triplicate, and a mean value of $\mathrm{BC}$ yield is given.

After fermentation, the cellulose pellicles were harvested and then washed by immersion in $0.1 \mathrm{~mol} / \mathrm{L} \mathrm{NaOH}$ at $80{ }^{\circ} \mathrm{C}$ for $4 \mathrm{~h}$ to remove bacteria and other impurities. The BC membranes were washed several times with distilled water to neutralize the $\mathrm{pH}$. Thereafter, the purified $\mathrm{BC}$ was lyophilized to calculate the $\mathrm{BC}$ production, and then maintained in a desiccator for the subsequent assay. BC production $(\mathrm{g} / \mathrm{L})$ was defined as the weight of $\mathrm{BC}$ production in $1 \mathrm{~L}$ medium.

\section{BC Structural Analysis}

BC morphology and microstructure were observed by field emission scanning electron microscopy (FESEM). The samples were divided into small fragments with a diameter of $0.5 \mathrm{~cm}$, sputter coated with gold, and observed at an accelerating voltage of 5 kV (Regulus 8220, Hitachi, Tokyo, Japan). Fourier transform infrared spectroscopy (FTIR) analysis was conducted to examine the chemical bond of the BC samples, in a spectral range of 400 to $4000 \mathrm{~cm}^{-1}$ (Vertex70, Bruker, Karlsruhe, Germany). The X-ray diffraction (XRD) technique was carried out to measure the crystalline structure of BC. Specimens were scanned from $2 \theta=5^{\circ}$ to $2 \theta=80^{\circ}$ at a scanning rate of $0.3^{\circ} \mathrm{s}$ using a diffractometer (Smartlab SE, Rigaku, Osaka, Japan). Segal peak height method (Segal et al. 1959; Wang et al. 2018) was used to calculated the crystallinity (usually referred to as the crystallinity index). The sample crystallinity was then calculated as 


$$
C=I_{002}-I_{\mathrm{am}} / I_{002} \times 100 \%
$$

where $C$ is crystallinity index; $I_{002}$ is the maximum intensity of the lattice diffraction at $2 \theta$ $\approx 22^{\circ}$; and $I_{a m}$ is the minimum intensity value of the peak at $2 \theta \approx 18^{\circ}$, which accounts for the amorphous part of the $\mathrm{BC}$.

\section{RESULTS AND DISCUSSION}

\section{Chemical Composition of Coconut Shell}

The total amount of carbohydrate, which varies according to the type and location of the feedstock, is an important index to evaluate the utilization value of raw materials. In this work, the coconut shell was composed of 57.13\% holocellulose, $27.42 \%$ lignin, $7.59 \%$ water, and $5.11 \%$ ash. The high content of holocellulose in the material offers the possibility of sugar production. In addition, the ash content in the material is relatively high, which deserves attention in the study of the high-value utilization of coconut shell. Some studies have shown that the concentrations of ions may affect microorganism growth and product formation (Mussatto and Roberto 2004; Hong et al. 2011).

\section{Preliminary Experiments of Coconut Shell Hydrolysis}

In previous reports, efficient hydrolysis has been obtained at an extremely low dosage of sulfuric acid ( $<0.1 \%$ mass fraction) and high reaction temperature (160 to 240 ${ }^{\circ} \mathrm{C}$ ), with a time range of 10 to $60 \mathrm{~min}$ (Ge et al. 2011, Kim et al. 2001; Xiang et al. 2003). In this assay, under the sulfuric acid condition of $0.05 \%$, the effects of temperature and time on hydrolysis were investigated by determining the conversion rate of holocellulose to reducing sugar, as well as the contents of sugar and microbial grow inhibitors. The results will provide the basis for further experiments of RSM.
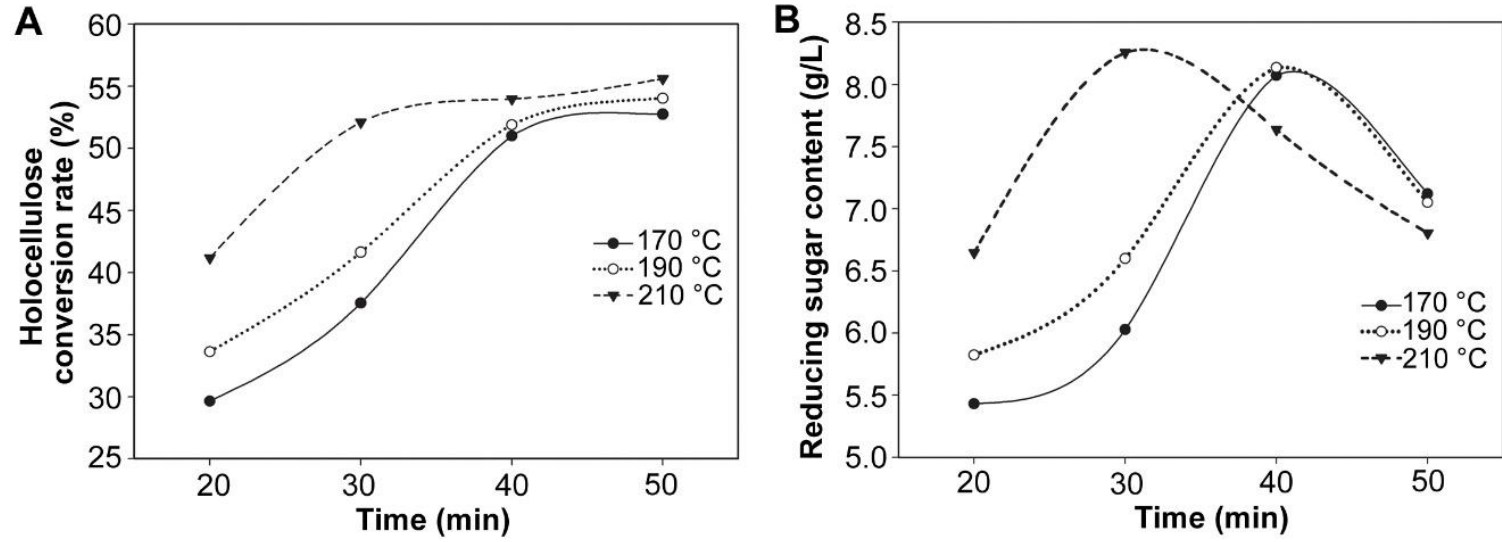

Fig. 2. Effect of time and temperature on the hydrolysis of coconut shell. (A) The conversion rate of holocellulose to the reducing sugar; (B) reducing sugar concentration

As the temperature and reaction time increased, the holocellulose conversion percentage increased, with a maximum of $55.6 \%$ at condition of $210{ }^{\circ} \mathrm{C}$ and $40 \mathrm{~min}$ (Fig. 2A). Notably, the RSC showed a general trend of first increasing and then decreasing over time at temperature conditions of 170,190 , and $210^{\circ} \mathrm{C}$, with peaks of $8.07,8.13$, and 8.25 $\mathrm{g} / \mathrm{L}$, respectively (Fig. 2B). At higher temperature, the RSC reached its maximum at earlier 
timepoints. These results were consistent with those of a previous study (Xiang et al. 2003) showing that with increasing temperature and time, both the synthesis and the decomposition of reducing sugar intensified, and the RSC decreased while the decomposition rate exceeded the formation rate.

Temperature and reaction time affect not only the reaction rate but also the composition of hydrolysate. Generally speaking, xylose showed the highest content in the hydrolysate, followed by arabinose, glucose, galactose, and mannose (Fig. 3 and Supplementary data). As the temperature increased and the reaction time was prolonged, the proportion of xylose was more than $40 \%$ in the RSC, with the maximum concentration of $3.20 \mathrm{~g} / \mathrm{L}$, accounting for $8.0 \%$ of the sample dry weight. This data indicated that hydrolysis of hemicellulose and cellulose are two independent reaction processes, and the former dominated in the hydrolysis of lignocellulose under mild conditions (Jacobsen and Wyman 2000; Xiang et al. 2003).
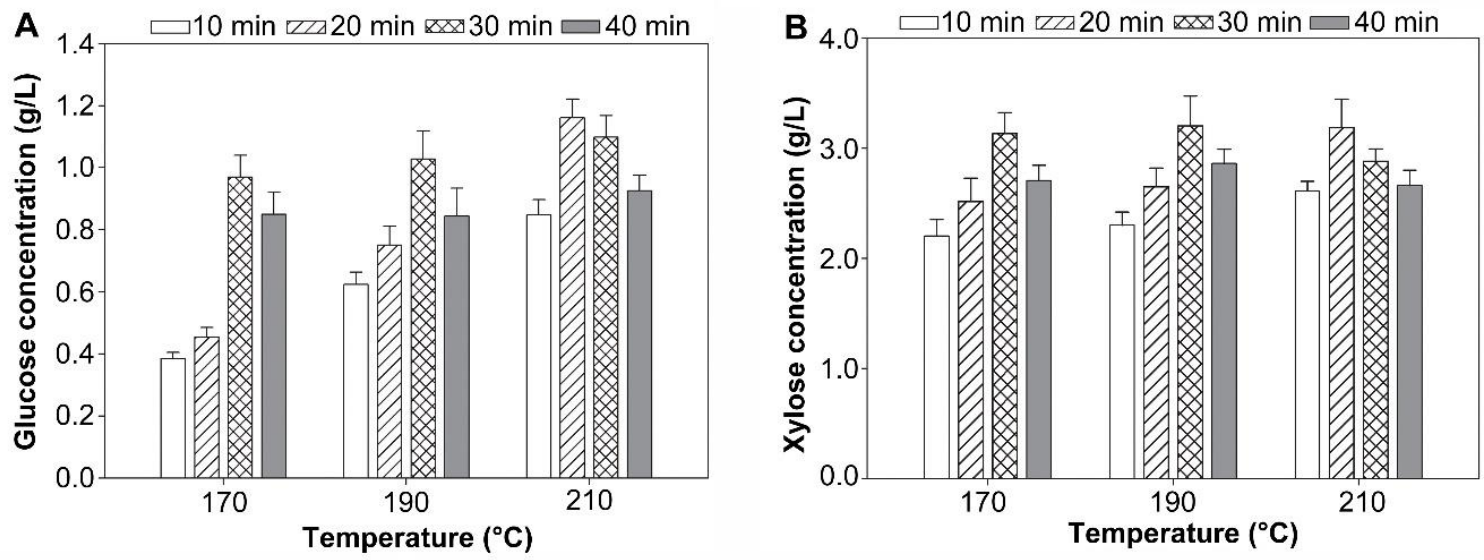

Fig. 3. Effect of time and temperature on sugar yield of coconut shell hydrolysis. (A) Glucose concentration. (B) Xylose concentration. (C) Arabinose concentration.

Previous studies suggested that both sugars and microbial growth inhibitors could be major factors affecting BC production (Hong et al. 2011; Kiziltas et al. 2015). In preliminary experiments, the side reaction has also been considered, especially at high temperature and low $\mathrm{pH}$. While the time and temperature increased in this study, the color of hydrolysate deepened (data not shown), probably because the vigorous treatment conditions intensified degradation of pentose, hexose and lignin, which generated colored substances and microbial growth inhibitors (Mussatto and Roberto 2004). In view of this, four microbial growth inhibitors, formic acid, acetic acid, furfural, and 5-HMF were determined when $\mathrm{RSC}$ reached a maximum at temperature 170,190 , and $210^{\circ} \mathrm{C}$. As shown in Table 2, formic acid exhibited the highest content, followed by acetic acid, furfural, and HMF, and the contents of these substances increased while the temperature was raised. Overall, these results indicated that a higher RSC could be obtained using vigorous reaction conditions in hydrolysis. Moreover, balancing the hydrolysis reaction and side reactions during lignocellulose hydrolysis is a problem worth exploring in the future. From the holistic perspective, the treatment condition of sulfuric acid dosage of $0.02 \%$ to $0.10 \%$ with temperature of 180 to $220^{\circ} \mathrm{C}$ and reaction time of 25 to 45 min was chosen in the following experiment of hydrolysis optimization by RSM. 
Table 2. Concentrations of Fermentation Inhibitors in Coconut Shell Hydrolysate under Different Treatment Conditions

\begin{tabular}{|l|l|l|l|l|}
\hline \multirow{2}{*}{$\begin{array}{l}\text { Treatment } \\
\text { condition }\end{array}$} & \multicolumn{4}{l|}{ Chemical composition $(\mathrm{g} / \mathrm{L})$} \\
\cline { 2 - 5 } & Formic acid & Acetic acid & Furfural & $5-\mathrm{HMF}^{\mathrm{a}}$ \\
\hline $170^{\circ} \mathrm{C}, 40 \mathrm{~min}$ & $1.17 \pm 0.08$ & $0.58 \pm 0.04$ & $0.21 \pm 0.01$ & $0.09 \pm 0.01$ \\
\hline $190^{\circ} \mathrm{C}, 40 \mathrm{~min}$ & $1.39 \pm 0.07$ & $0.61 \pm 0.05$ & $0.25 \pm 0.02$ & $0.12 \pm 0.01$ \\
\hline $210^{\circ} \mathrm{C}, 30 \mathrm{~min}$ & $1.41 \pm 0.03$ & $0.72 \pm 0.06$ & $0.26 \pm 0.02$ & $0.16 \pm 0.01$ \\
\hline
\end{tabular}

5-HMFa: 5-hydroxymethylfurfural

\section{Hydrolysis Optimization by RSM}

Here, the aim of the hydrolyzing process optimization was conducted as having maximum responses values of RSC. The experimental design according to BBD and the responses obtained from 17 different combinations of reaction conditions are shown in Table 3. The regression equation of RSC by the experimental responses in terms of actual factors was displayed as,

$$
\begin{aligned}
\mathrm{RSC}= & -51.30187+188.21250 X_{1}+0.40312 X_{2}+0.80178 X_{3}-0.50625 X_{1} X_{2} \\
& -1.04375 X_{1} X_{3}-1.48750 \mathrm{E}^{-003} X_{2} X_{3}-380.93750 X_{1}^{2}-7.98750 \mathrm{E}^{-004} X_{2}{ }^{2} \\
& -6.77000 \mathrm{E}^{-003} X_{3}{ }^{2}
\end{aligned}
$$

where the sulfuric acid concentration, reaction temperature, and reaction time were coded as $X_{1}, X_{2}$, and $X_{3}$, respectively.

Table 3. Independent Variables and the Results of Response Surface Analysis

\begin{tabular}{|l|l|l|l|l|}
\hline Run & $\begin{array}{l}\text { Sulfuric acid } \\
\text { concentration }(\%)\end{array}$ & Temperature $\left({ }^{\circ} \mathrm{C}\right)$ & Time $(\mathrm{min})$ & $\begin{array}{l}\text { Reducing sugar } \\
\text { concentration }(\mathrm{g} / \mathrm{L})\end{array}$ \\
\hline 1 & 0.10 & 220.00 & 35.00 & 7.19 \\
\hline 2 & 0.02 & 200.00 & 25.00 & 6.79 \\
\hline 3 & 0.10 & 180.00 & 35.00 & 8.03 \\
\hline 4 & 0.06 & 200.00 & 35.00 & 8.37 \\
\hline 5 & 0.06 & 220.00 & 25.00 & 8.06 \\
\hline 6 & 0.06 & 220.00 & 45.00 & 6.84 \\
\hline 7 & 0.06 & 180.00 & 25.00 & 7.34 \\
\hline 8 & 0.06 & 200.00 & 35.00 & 8.42 \\
\hline 9 & 0.06 & 180.00 & 45.00 & 7.31 \\
\hline 10 & 0.02 & 200.00 & 45.00 & 6.96 \\
\hline 11 & 0.02 & 220.00 & 35.00 & 7.69 \\
\hline 12 & 0.10 & 200.00 & 25.00 & 8.07 \\
\hline 13 & 0.06 & 200.00 & 35.00 & 8.30 \\
\hline 14 & 0.02 & 180.00 & 35.00 & 6.91 \\
\hline 15 & 0.06 & 200.00 & 35.00 & 8.44 \\
\hline 16 & 0.10 & 200.00 & 45.00 & 6.57 \\
\hline 17 & 0.06 & 200.00 & 35.00 & 8.39 \\
\hline
\end{tabular}

As shown in Fig. 4, the adequacy between the observed and predicted results illustrated a strong linear relationship between the actual and predicted response. The coefficient of determination $\mathrm{R}^{2}$ was 0.9953 , indicated that $99.53 \%$ of the variability in the responses can be explained by the model (Wang et al. 2018). 


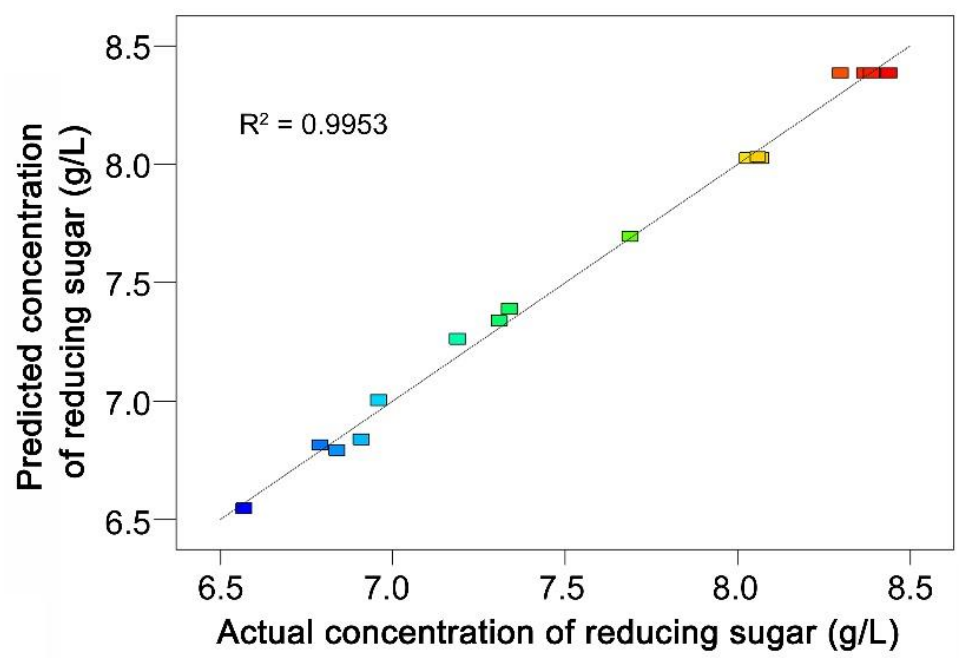

Fig. 4. Predicted response values versus the actual response values of reducing sugar concentration

ANOVA was used to evaluate the adequacy of the model (Table 4). The F-value of 165.60 implied that the model was significant. There was only $0.01 \%$ chance that a "Model F-Value" could occur due to noise. The p-value represents the significance of the variables, and the smaller the p-value, the higher the significance of the variable. P-values less than 0.0500 indicate model terms are significant, while values greater than 0.1000 indicate the model terms are not significant. In this case $X_{1}, X_{3}, X_{1} X_{2}, X_{1} X_{3}, X_{2} X_{3}, X_{1}{ }^{2}, X_{2}^{2}$, and $X_{3}{ }^{2}$ were significant model terms. The "Predicted R-Squared" of 0.9487 was in reasonable agreement with the "Adjusted R-Squared" of 0.9893, suggesting a good agreement between the predicted and the observed values. "Adeq Precision" measures the signal to noise ratio. A ratio greater than 4 is desirable. The ratio of 34.562 showed an adequate signal to noise ratio. Moreover, the "Lack of Fit F-value" of 2.49 implied Lack of Fit was not significant relative to the pure error. There was only a $19.91 \%$ chance that a "Lack of Fit F-value" could occur due to noise.

Table 4. ANOVA for Response Surface Quadratic Model

\begin{tabular}{|l|l|l|l|l|l|l|}
\hline Source & $\begin{array}{l}\text { Sum of } \\
\text { Squares }\end{array}$ & $\begin{array}{l}\text { Degree of } \\
\text { Freedom }\end{array}$ & Mean Square & F Value & $\begin{array}{l}\text { p-value } \\
\text { Prob }>\mathrm{F}\end{array}$ & \\
\hline Model & 7.16 & 9 & 0.80 & 165.60. & $<0.0001$ & significant \\
\hline$X_{1}$ & 0.29 & 1 & 0.29 & 59.30 & 0.0001 & \\
\hline$X_{2}$ & $4.512 \mathrm{E}^{-003}$ & 1 & $4.512 \mathrm{E}^{-003}$ & 0.94 & 0.3649 & \\
\hline$X_{3}$ & 0.83 & 1 & 0.83 & 173.11 & $<0.0001$ & \\
\hline$X_{1} X_{2}$ & 0.66 & 1 & 0.66 & 136.50 & $<0.0001$ & \\
\hline$X_{1} X_{3}$ & 0.70 & 1 & 0.70 & 145.06 & $<0.0001$ & \\
\hline$X_{2} X_{3}$ & 0.35 & 1 & 0.35 & 73.66 & $<0.0001$ & \\
\hline$X_{1}{ }^{2}$ & 1.56 & 1 & 1.56 & 325.43 & $<0.0001$ & \\
\hline$X_{2}{ }^{2}$ & 0.43 & 1 & 0.43 & 89.42 & $<0.0001$ & \\
\hline$X_{3}{ }^{2}$ & 1.93 & 1 & 1.93 & 401.51 & $<0.0001$ & \\
\hline Residual & 0.034 & 7 & $4.806 \mathrm{E}^{-003}$ & & & \\
\hline Lack of Fit & 0.022 & 3 & $7.308 \mathrm{E}^{-003}$ & 2.49 & 0.1991 & not \\
& & & & & & \\
\hline Pure Error & 0.012 & 4 & $2.930 \mathrm{E}^{-003}$ & & & \\
\hline Cor Total & 7.12 & 16 & & & & \\
\hline
\end{tabular}


The effects of sulfuric acid concentration $\left(X_{1}\right)$, reaction temperature $\left(X_{2}\right)$, and reaction time $\left(X_{3}\right)$ on RSC are shown in response surfaces and contour plots in Fig. 5. As shown in contour plot, the RSC kept rising and then slightly declined with the sulfuric acid concentration increasing from $0.04 \%$ to $0.10 \%$ mass fraction (Fig. 5A and 5B). When the sulfuric acid concentration was larger than the optimal value, higher temperature and longer reaction time resulted in the lower RSC, which indicated significant interactions of sulfuric acid concentration with temperature and time. These results were consistent with that in Fig. 1. Unexpectedly, with the increase of temperature at a certain concentration of sulfuric acid or a certain reaction time, the RSC exhibited a slight increase and decline (Fig. 5A and 5C). This result was correlated with the ANOVA data and RSC Eq. (4), that temperature (the linear term) had no obvious influence on the RSC in this study. However, the quadratic term of temperature $\left(X_{2}^{2}\right)$ and the interaction terms of temperature with sulfuric acid concentration $\left(X_{1} X_{2}\right)$ and reaction time $\left(X_{2} X_{3}\right)$ had significant impacts on RSC.
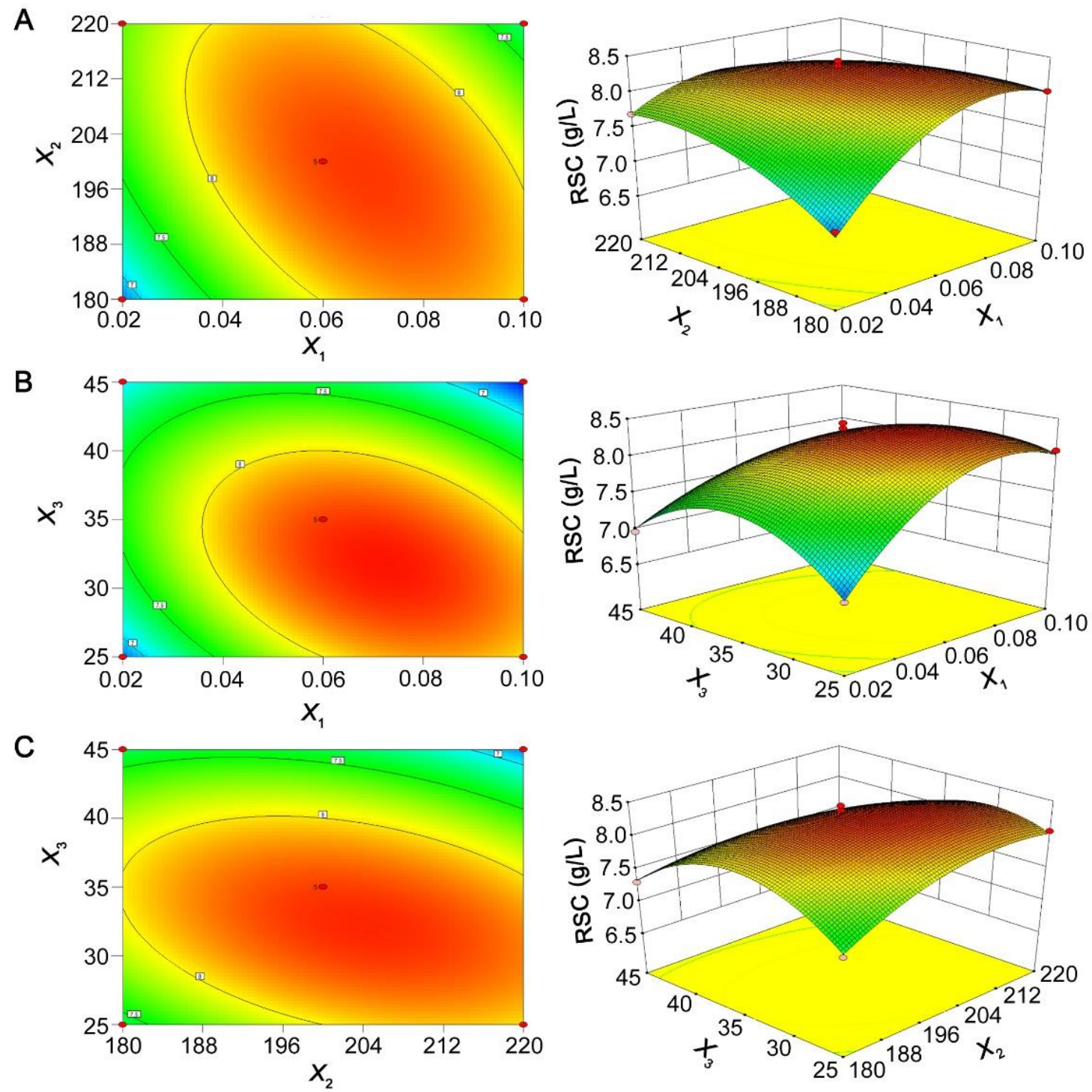

Fig. 5. Contour and 3D response surface plots obtained by RSM 
According to the model, the predicted optimum RSC was $8.46 \mathrm{~g} / \mathrm{L}$, which could be obtained under $0.07 \%$ sulfuric acid treatment at $200.50{ }^{\circ} \mathrm{C}$, for $31.77 \mathrm{~min}$. The predicted value was verified by parallel experiments, which were conducted at $200{ }^{\circ} \mathrm{C}$ for $32 \mathrm{~min}$ with a solution of $0.07 \%$ sulfuric acid. The results showed that the RSC reached to 8.39 $\mathrm{g} / \mathrm{L}$, which was close to the predicted value of the model. Furthermore, the holocellulose conversion rate was $56.1 \%$ at this condition.

\section{Detoxification of Coconut Shell Hydrolysate}

Hydrolysate without detoxification cannot be used as a carbon source in BC fermentation (Hong et al. 2011; Kiziltas et al. 2015). Activated charcoal, $\mathrm{Ca}(\mathrm{OH})_{2}, \mathrm{NaOH}$, and ammonium hydroxide remove some inhibitors efficiently in acid hydrolysates, and the methods have been well established (Mussatto and Roberto 2004; Hong et al. 2011; Guo et al. 2013). In this study, a mixed detoxification method using activated charcoal and $\mathrm{Ca}(\mathrm{OH})_{2}$ was explored. The effects of $\mathrm{pH}$ and activated charcoal dosage on removing fermentation inhibitors from the hydrolysate were studied; sugar loss and BC synthesis after detoxification were evaluated.

The contents of fermentation inhibitors in hydrolysate decreased gradually as the dose of activated charcoal increased, under any $\mathrm{pH}$ condition (Table 5 and Supplementary data). The hydrolysate at pH 5.0 exhibited higher efficiency in removing microbial growth inhibitors, as inhibitor adsorption on activated charcoal is quite sensitive to changes in $\mathrm{pH}$ and weak organic acids are most readily adsorbed at low pH (Mussatto and Roberto 2004). Specifically, the contents of furfural and 5-HMF were reduced $15.5 \%$ and $19.1 \%$ at activated charcoal dosage of $1 \mathrm{~g} / \mathrm{L}$, while the changes in that of formic acid and acetic acid were slight (within 5\%). When added activated charcoal dose to $2 \mathrm{~g} / \mathrm{L}$, the content of furfural and 5-HMF were decreased by $44.4 \%$ and $65.1 \%$, respectively, indicating that activated charcoal had good adsorption capacity for these two inhibitors under this condition. In the same treatment, only $24.8 \%$ and $17.1 \%$ of formic acid and acetic acid were removed. In the presence of 3 and $4 \mathrm{~g} / \mathrm{L}$ concentration of activated charcoal, furfural and 5-HMF levels were virtually undetectable, while formic acid and acetic acid levels were reduced by approximately $30 \%$. These results were in consistent with former studies, in which activated carbon showed different adsorption capacity for the fermentation inhibitors, that, formic acid and acetic acid are more difficult to remove compared with furfural and HMF (Ge et al. 2011; Guo et al. 2013; Cheng et al. 2017).

In activated charcoal adsorption, monosaccharides and the RSC could suffer certain degrees of loss, which were aggravated with increasing dose of activated charcoal (Table. 5 ). The results were not exactly consistent with the previous reports, which had indicated that activated charcoal treatment did not affect the sugar concentration very much while removed most of the furan aldehydes and the phenols (Guo et al. 2013). Specifically, the maximum reduction $(8.8 \%)$ in $\mathrm{RSC}$ was found in treatment of $4 \mathrm{~g} / \mathrm{L}$ activated charcoal dosage, at which dosage the glucose, arabinose, galactose, xylose, and mannose were decreased by $13.6 \%, 13.4 \%, 18.0 \%, 5.8 \%$, and $25.6 \%$, respectively. In addition, because of the low basic levels, the loss of galactose and mannose in hydrolysate detoxification had little effect on the RSC. These results showed that activated charcoal treatment cut both ways, removing fermentation inhibitors and reducing sugar levels. Therefore, in the process of detoxification of acid hydrolysis, eliminating fermentation inhibition while minimizing sugar loss should be considered.

Liu et al. (2021). "Bacterial cellulose from coconut shell," BioResources 16(1), 1042-1062. 1052 
Table 5. Concentrations of Sugars and Fermentation Inhibitors in Detoxified Hydrolysate of Coconut Shell Under Different Treatment Conditions at $\mathrm{pH} 5$

\begin{tabular}{|c|c|c|c|c|c|c|c|c|c|}
\hline \multirow{2}{*}{$\begin{array}{c}\text { Chemical } \\
\text { Composition } \\
(\mathrm{g} / \mathrm{L})\end{array}$} & \multicolumn{9}{|c|}{ Dosage of Activated Carbon ( $\mathrm{g} / \mathrm{L})$ and Removal Rates (\%) } \\
\hline & 0 & 1 & $\begin{array}{l}\text { Removal } \\
\text { Rate }\end{array}$ & 2 & $\begin{array}{l}\text { Removal } \\
\text { Rate }\end{array}$ & 3 & $\begin{array}{c}\text { Removal } \\
\text { Rate }\end{array}$ & 4 & $\begin{array}{c}\text { Removal } \\
\text { Rate }\end{array}$ \\
\hline Formic acid & $1.49 \pm 0.05$ & $1.44 \pm 0.05$ & 3.53 & $1.12 \pm 0.04$ & 24.75 & $1.05 \pm 0.07$ & 29.89 & $1.01 \pm 0.05$ & 32.20 \\
\hline Acetic acid & $0.70 \pm 0.05$ & $0.67 \pm 0.02$ & 4.63 & $0.58 \pm 0.03$ & 17.07 & $0.57 \pm 0.05$ & 19.60 & $0.49 \pm 0.03$ & 28.98 \\
\hline Furfural & $0.27 \pm 0.02$ & $0.23 \pm 0.01$ & 15.48 & $0.12 \pm 0.01$ & 44.39 & $\approx 0$ & $\approx 100 \%$ & - & - \\
\hline 5-HMFa & $0.15 \pm 0.01$ & $0.12 \pm 0.01$ & 19.11 & $0.05 \pm 0.01$ & 65.13 & $\approx 0$ & $\approx 100 \%$ & - & - \\
\hline Glucose & $1.25 \pm 0.04$ & $1.16 \pm 0.03$ & 7.07 & $1.11 \pm 0.05$ & 11.39 & $1.09 \pm 0.04$ & 13.04 & $1.08 \pm 0.07$ & 13.57 \\
\hline Arabinose & $2.40 \pm 0.10$ & $2.23 \pm 0.06$ & 7.06 & $2.20 \pm 0.07$ & 8.39 & $2.18 \pm 0.03$ & 9.06 & $2.08 \pm 0.08$ & 13.36 \\
\hline Galactose & $0.39 \pm 0.02$ & $0.36 \pm 0.02$ & 7.78 & $0.35 \pm 0.01$ & 10.06 & $0.35 \pm 0.02$ & 10.19 & $0.31 \pm 0.02$ & 18.03 \\
\hline Xylose & $3.29 \pm 0.09$ & $3.19 \pm 0.08$ & 2.97 & $3.20 \pm 0.07$ & 2.77 & $3.12 \pm 0.08$ & 5.13 & $3.10 \pm 0.09$ & 5.79 \\
\hline Mannose & $0.18 \pm 0.02$ & $0.15 \pm 0.01$ & 15.89 & $0.14 \pm 0.01$ & 21.48 & $0.14 \pm 0.01$ & 22.05 & $0.13 \pm 0.01$ & 25.58 \\
\hline Reducing sugar & $8.32 \pm 0.15$ & $7.98 \pm 0.13$ & 4.13 & $7.90 \pm 0.22$ & 5.05 & $7.82 \pm 0.09$ & 5.89 & $7.59 \pm 0.10$ & 8.77 \\
\hline
\end{tabular}

5-HMFa: 5-hydroxymethylfurfural. 


\section{Synthesis of BC Using Hydrolysate as Carbon Source}

$\mathrm{BC}$ production is essential in the assessment of hydrolysate detoxification. For comparison, the RSC in coconut shell hydrolysate (detoxified or not) was diluted to 5.0 $\mathrm{g} / \mathrm{L}$. After fermentation for 7 days, the highest yield $(1.87 \mathrm{~g} / \mathrm{L})$ of BC showed in substrate with $5.0 \mathrm{~g} / \mathrm{L}$ glucose as control (Fig. 6A). Significantly lower yields were observed in medium with hydrolysate that was not detoxified, probably due to the high amount of fermentation inhibitors. When furfural and 5-HMF were almost totally removed by 3 or 4 $\mathrm{g} / \mathrm{L}$ activated carbon, the $\mathrm{BC}$ yield reached 1.62 and $1.66 \mathrm{~g} / \mathrm{L}$, respectively, even though formic acid and acetic acid levels were only $30 \%$ decreased. These results suggest that furfural and 5-HMF have more important effects on BC synthesis compared with formic acid and acetic acid, even at low concentrations. Thus, in the presence of $3 \mathrm{~g} / \mathrm{L}$ dosage of activated carbon, the fermentation inhibitors were effectively removed, while an acceptable yield of $\mathrm{BC}$ was achieved despite the loss of sugar.
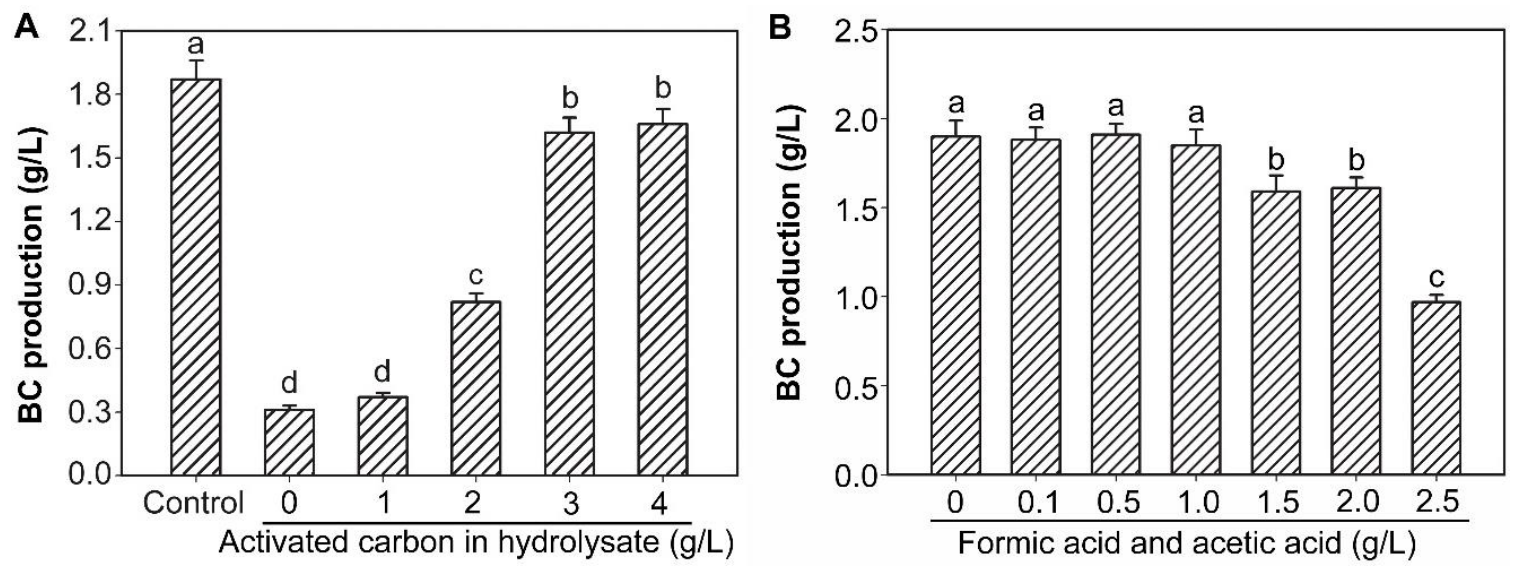

Fig. 6. (A) BC production using control and detoxified hydrolysate media. (B) Effect of formic acid and acetic acid on BC production. Means \pm SDs are plotted. Bars labeled with different letters indicate that the mean values are significantly different $(P<0.05)$.

\section{Effect of Formic and Acetic Acid on BC Production}

To investigate the effect of formic acid and acetic acid on $\mathrm{BC}$ production, the acids were added exogenously to the control medium at different concentrations, and the $\mathrm{BC}$ production were compared (Fig. 6B). When the acid concentration was increased from 0 to $1.0 \mathrm{~g} / \mathrm{L}$, the $\mathrm{BC}$ production showed no reduction relative to that in control. After adding the two acids to concentrations of 1.5 and $2.0 \mathrm{~g} / \mathrm{L}$, the $\mathrm{BC}$ production decreased by about $15 \%$. This result is similar to that of the $\mathrm{BC}$ yield prepared by detoxified hydrolysate in Fig. 3. The medium with $2.5 \mathrm{~g} / \mathrm{L}$ acid exhibited only about $0.97 \mathrm{~g} / \mathrm{L}$ BC, which was almost $1 / 2$ that observed in control. These results suggested that formic acid and acetic acid at high concentrations could obviously inhibited the fermentation for BC.

Furthermore, higher amounts of formic acid and acetic acid were required in this assay to negatively affect the yield of $\mathrm{BC}$, compared with hydrolysates. This may be due to the presence of other fermentation inhibitors that have not determined in the hydrolysate, such as levulinic acid and phenolic compounds. Another possibility could be that there is a synergistic effect in the compounds of inhibitors, thus enhancing the inhibitory effect (Palmqvist et al. 1999; Mussatto and Roberto 2004). 


\section{Effect of Adding Extra Carbon Sources on BC Production Using the Hydrolysate}

Previous studies have shown good results by adding additional sugar to the hydrolysate of renewable cellulosic wastes, and in these attempts, glucose, fructose, mannose, and sucrose were good choices (Dahman et al. 2010; Santos et al. 2013; Mohammadkazemi et al. 2015). In this study, glucose, fructose, and sucrose greatly increased the yield of BC (Fig. 7A), similar to previous results (Dahman et al. 2010). However, the effect of mannose was not as obvious as that of the other sugars in this assay, which differed from previous studies (Huang et al. 2015; Mohammadkazemi et al. 2015). Therefore, an appropriate supplementation of sugar could be used as a method to enhance the $\mathrm{BC}$ yield when using coconut shell hydrolysate as carbon source.

Next, the fermentation of $\mathrm{BC}$ by using detoxified hydrolysate for a long time was investigated. In view of the low sugar concentration in the hydrolysate, glucose was added to bring the final RSC to $20 \mathrm{~g} / \mathrm{L}$. At the same time, the effect of $\mathrm{pH}$ on $\mathrm{BC}$ production was considered (Ye et al. 2019). Figure 7B shows that the yield of BC increased rapidly within 14 days of culture, while that increased slowly within 14 to 21 days. This suggested a high consumption of nutrients after 14 days of fermentation. After 21-day cultivation in medium using glucose and medium using composited carbon source, the final $\mathrm{BC}$ yield reached 5.34 and $5.30 \mathrm{~g} / \mathrm{L}$, with no significant change. Compared to Fig. 6A and Fig. 7A, the data obtain in this assay suggested that the effect of microbial growth inhibitors on BC synthesis was reduced by prolonged fermentation at high reducing sugar concentration. In summary, these results indicated the potential in utilizing the hydrolysate of coconut shell for BC production in long-term cultivation.
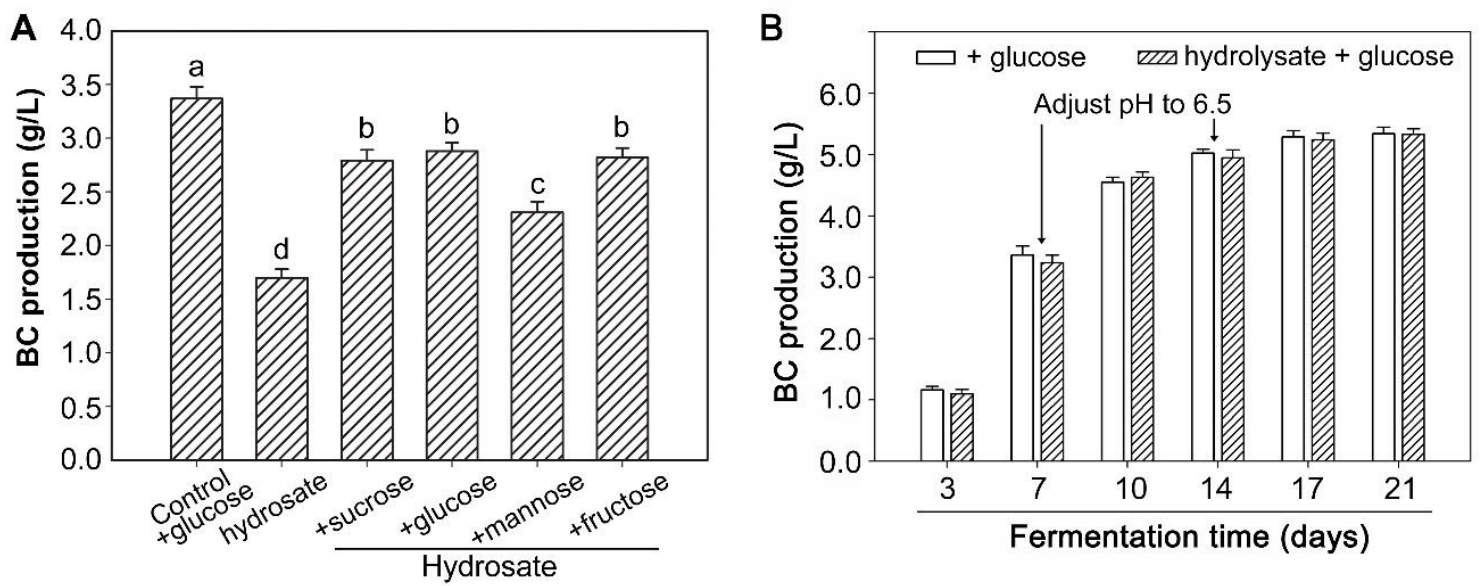

Fig. 7. (A) Various extra carbon sources on $B C$ production. (B) $B C$ production in 21 days using carbon source of glucose or composite carbon source of hydrolysate and glucose. Means \pm SDs are plotted. Bars labeled with different letters indicate that the mean values are significantly different $(P<0.05)$.

\section{Morphological and Structural Analysis of BC}

SEM results showed that BC prepared from hydrolysate of coconut shell as carbon source exhibited a dense network of interwoven ultrafine fibrils of nanometer size (Fig. 8). This result was in agreement with previous studies using other raw wastes (Lin et al. 2014; Yang et al. 2014; Li et al. 2015). X-ray diffraction (XRD) patterns were explored to determine the crystalline structure of the $\mathrm{BC}$. All of the $\mathrm{BC}$ samples were characterized as 
cellulose I (Fig. 9A), with peaks at $2 \theta$ angles of $14.7,18.4$, and $22.6^{\circ}$ for BC obtained from control medium, $2 \theta$ angles of $14.7,18.2$ and $22.8^{\circ}$ for $\mathrm{BC}$ obtained from medium with detoxified hydrolysate. The crystallinity index of $\mathrm{BC}$ from medium of control and medium with detoxified hydrolysate was 81.42 and 74.80, respectively, which indicated similar crystalline morphology of the polymers.

According to the FT-IR spectroscopy results (Fig. 9 B), the absorption peak at 3290 $\mathrm{cm}^{-1}$ reflects the $\mathrm{O}-\mathrm{H}$ stretching, $2916 \mathrm{~cm}^{-1}$ indicates $\mathrm{C}-\mathrm{H}$ stretching, $1643 \mathrm{~cm}^{-1}$ indicates $\mathrm{C}-\mathrm{O}-\mathrm{C}$ stretching, and $1022 \mathrm{~cm}^{-1}$ indicates $\mathrm{C}-\mathrm{O}$ stretching. The results were similar to previous studies (Yang et al. 2014; Kiziltas et al. 2015; Jahan et al. 2018). There was no obvious difference between BC samples obtained from the reference medium and medium with hydrolysate of coconut shell, suggesting that carbon source had no effect on the structure of BC samples.
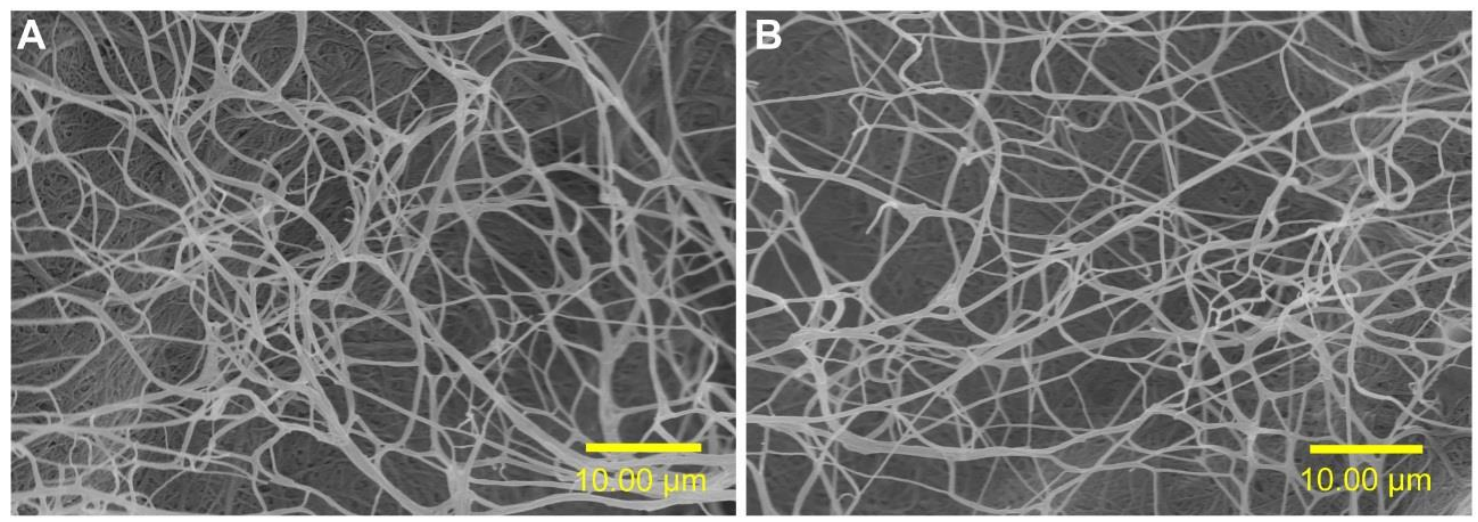

Fig. 8. FE-SEM pictures of $B C$ samples collected from different fermentation medium: (A) product obtained from control medium; (B) product obtained from medium with detoxified hydrolysate

A

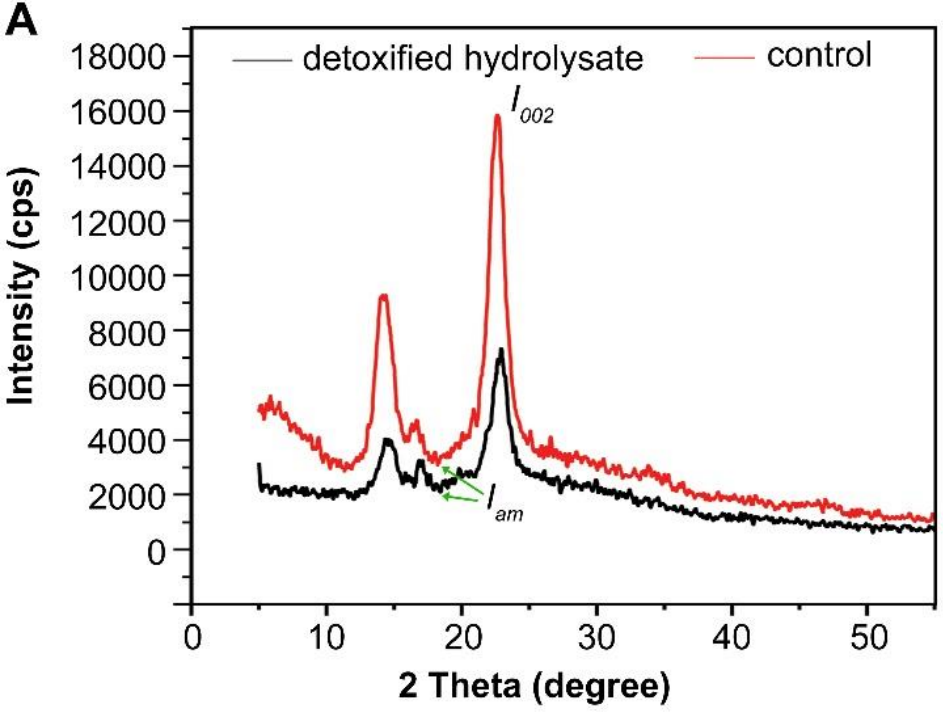

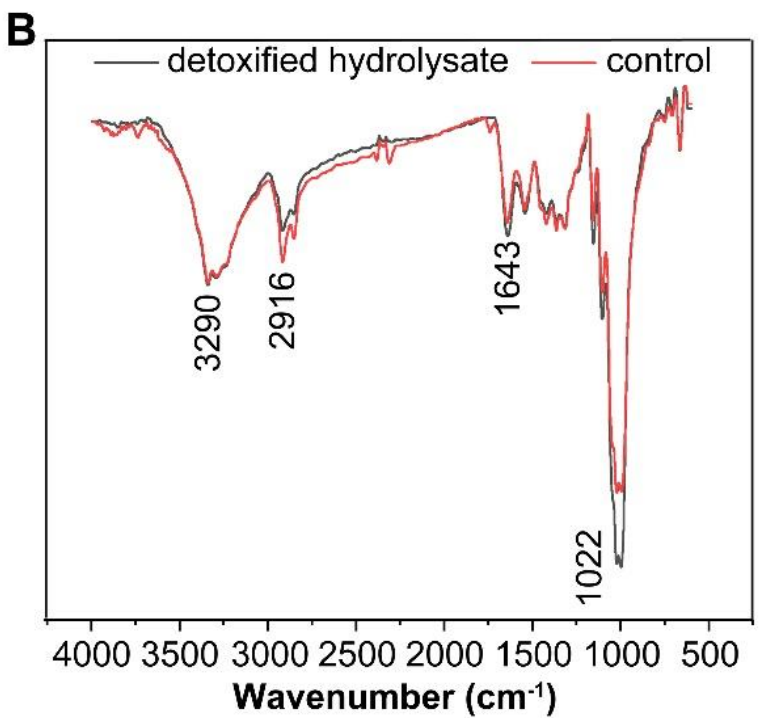

Fig. 9. XRD patterns $(A)$ and FTIR spectra $(B)$ of $B C$ samples collected from different static fermentation 


\section{CONCLUSIONS}

1. This study showed the potential of utilizing coconut shell for production of bacterial cellulose (BC). Methods for hydrolyzing coconut shell with ultra-low mass fraction of sulfuric acid and detoxification of the hydrolysate were established.

2. The results suggested both sugars and microbial growth inhibitors could be major factors affecting BC production.

3. By adding extra carbon sources, the yield of BC was greatly increased in both substrates of control and hydrolysate. In the 21-day BC fermentation with medium using glucose and medium using composited carbon source of glucose and hydrolysate, the final $\mathrm{BC}$ yield reached 5.34 and $5.30 \mathrm{~g} / \mathrm{L}$.

4. Structural analysis revealed similar properties of BC produced from control and medium with the hydrolysate.

\section{ACKNOWLEGEMENTS}

The research was supported by National Natural Science Foundation of China (Grant No. 31800219, 31770626, 31600472), the National Key Research and Development Program of China (2017YFB0307900), and the Foundation (ZZ20200126) of State Key Laboratory of Biobased Material and Green Papermaking, Qilu University of Technology, Shandong Academy of Sciences.

\section{REFERENCES CITED}

Campano, C., Balea, A., Blanco, A., and Negro, C. (2015). "Enhancement of the fermentation process and properties of bacterial cellulose: A review," Cellulose 23, 57-91. DOI: 10.1007/s10570-015-0802-0

Cheng, Z., Yang, R. D., and Liu, X. (2017). "Production of bacterial cellulose by Acetobacter xylinum through utilizing acetic acid hydrolysate of bagasse as low-cost carbon source," BioResources 12(1), 1190-1200. DOI: 10.15376/biores.12.1.11901200

Cheng, Z., Yang, R. D., Liu, X., Liu, X., and Chen, H. (2017). 'Green synthesis of bacterial cellulose via acetic acid pre-hydrolysis liquor of agricultural corn stalk used as carbon source," Bioresource Technology 234(2017), 8-14. DOI:

10.1016/j.biortech.2017.02.131

Dahman, Y., Jayasuriya, K. E., and Kalis, M. (2010). "Potential of biocellulose nanofibers production from agricultural renewable resources: Preliminary study," Applied Biochemistry and Biotechnology 162(6), 1647-1659. DOI: 10.1007/s12010010-8946-8

El-Saied, H., Basta, A. H., and Gobran, R. H. (2004). "Research progress in friendly environmental technology for the production of cellulose products (bacterial cellulose and its application)," Polymer-Plastics Technology and Engineering 43(3), 797-820. DOI: $10.1081 /$ ppt-120038065 
Esa, F., Tasirin, S. M., and Rahman, N. A. (2014). "Overview of bacterial cellulose production and application," Agriculture and Agricultural Science Procedia 2, 113119. DOI: 10.1016/j.aaspro.2014.11.017

Gallegos, A. M. A., Carrera, S. H., Parra, R., Keshavarz, T., and Iqbal, H. M. N. (2016). "Bacterial cellulose: A sustainable source to develop value-added products - A review," BioResources 11(2), 5641-5655. DOI: 10.15376/biores.11.2.5641-5655

Ge, J. P., Liu, G. M., Sun, H. B., Ling, H. Z., Yang, X. F., Fang, B. Z., and Ping, W. X. (2011). "Effect of the activated charcoal on corncob hemicellulose hydrolysate detoxification," Microbiology China 38, 629-634. DOI: 10.13344/j.microbiol.china.2011.05.001.

Guo, X., Cavka, A., Jonsson, L. J., and Hong, F. (2013). "Comparison of methods for detoxification of spruce hydrolysate for bacterial cellulose production," Microbial Cell Factories 12(1), Article number 93 (2013). DOI: /10.1186/1475-2859-12-93

Hong, F., and Qiu, K. (2008). “An alternative carbon source from konjac powder for enhancing production of bacterial cellulose in static cultures by a model strain Acetobacter aceti subsp. xylinus ATCC 23770," Carbohydrate Polymers 72(3), 545549. DOI: 10.1016/j.carbpol.2007.09.015

Hong, F., Zhu, Y. X., Yang, G., and Yang, X. X. (2011). "Wheat straw acid hydrolysate as a potential cost-effective feedstock for production of bacterial cellulose," Journal of Chemical Technology \& Biotechnology 86(5), 675-680. DOI: 10.1002/jctb.2567

Huang, C., Yang, X. Y., Xiong, L., Guo, H. J., Luo, J., Wang, B., Zhang, H. R., Lin, X. Q., and Chen, X. D. (2015). "Utilization of corncob acid hydrolysate for bacterial cellulose production by Gluconacetobacter xylinus," Applied Biochemistry and Biotechnology 175(3), 1678-1688. DOI: 10.1007/s12010-014-1407-z

Jacobsen, S. E., and Wyman, C. E. (2000). "Cellulose and hemicellulose hydrolysis models for application to current and novel pretreatment processes," Applied Biochemistry and Biotechnology 84-86(1-9), 16. DOI: 10.1385/abab:84-86:1-9:81

Jahan, F., Kumar, V., and Saxena, R. K. (2018). "Distillery effluent as a potential medium for bacterial cellulose production: A biopolymer of great commercial importance," Bioresource Technology 250, 922-926. DOI: 10.1016/j.biortech.2017.09.094

Kanojia, A., and Jain, S. K. (2017). "Performance of coconut shell as coarse aggregate in concrete," Construction and Building Materials 140, 150-156. DOI: 10.1016/j.conbuildmat.2017.02.066

Kim, S. J., Lee, Y. Y., and Torget, R. W. (2001). "Cellulose hydrolysis under extremely low sulfuric acid and high-temperature conditions," Applied Biochemistry and Biotechnology 91-93(1-9), 331-340. DOI: 10.1385/abab:91-93:1-9:331

Kim, S. S., Lee, S. Y., Park, K. J., Park, S. M., An, H. J., Hyun, J. M., and Choi, Y. H. (2017). "Gluconacetobacter sp. gel_SEA623-2, bacterial cellulose producing bacterium isolated from citrus fruit juice," Saudi Journal of Biological Sciences 24(2), 314-319. DOI: 10.1016/j.sjbs.2015.09.031

Kiziltas, E. E., Gardner, A., and Gardner, D. J. (2015). "Synthesis of bacterial cellulose using hot water extracted wood sugars," Carbohydrate Polymers 124, 131-138. DOI: 10.1016/j.carbpol.2015.01.036

Kucińska-Lipka, J., Gubanska, I., and Janik, H. (2015). "Bacterial cellulose in the field of wound healing and regenerative medicine of skin: Recent trends and future prospectives," Polymer Bulletin 72(9), 2399-2419. DOI: 10.1007/s00289-015-1407-3 
Li, Z., Wang, L., Hua, J., Jia, S., Zhang, J., and Liu, H. (2015). "Production of nano bacterial cellulose from waste water of candied jujube-processing industry using Acetobacter xylinum," Carbohydrate Polymers 120, 115-119. DOI: 10.1016/j.carbpol.2014.11.061

Lin, D., Lopez-Sanchez, P., Li, R., and Li, Z. (2014). "Production of bacterial cellulose by Gluconacetobacter hansenii CGMCC 3917 using only waste beer yeast as nutrient source," Bioresource Technology 151, 113-119. DOI: 10.1016/j.biortech.2013.10.052

Lin, D. H., Liu, Z., Shen, R., Chen, S. Q., and Yang, X. B. (2020). "Bacterial cellulose in food industry: Current research and future prospects," International Journal of Biological Macromolecules 158, 1007-1019. DOI: 10.1016/j.ijbiomac.2020.04.230

Liu, R. C., Huang, G. M., Yao, B. Y., and Dou, Z. F. (2006). "Preparation of xylose from coconut shell by normal pressure acid hydrolysis," Food Sciences 27, 263-267. (in Chinese with English abstract)

Menon, V., and Rao, M. (2012). "Trends in bioconversion of lignocellulose: Biofuels, platform chemicals \& biorefinery concept," Progress in Energy and Combustion Science, 38(4), 522-550. DOI: 10.1016/j.pecs.2012.02.002

Miller, G.L. (1959). "Use of dinitrosalicylic acid reagent for determination of reducing sugar," Analytical Chemistry 31(3), 426-428. DOI: 10.1021/ac60147a030

Mohammadkazemi, F., Azin, M., and Ashori, A. (2015). "Production of bacterial cellulose using different carbon sources and culture media," Carbohydrate Polymers 117, 518-523. DOI: 10.1016/j.carbpol.2014.10.008

Mussatto, S. I., and Roberto, I. C. (2004). "Alternatives for detoxification of diluted-acid lignocellulosic hydrolyzates for use in fermentative processes: A review," Bioresource Technology 93(1), 1-10. DOI: 10.1016/j.biortech.2003.10.005

Palanisamy, M., Kolandasamy, P., Awoyera, P., Gobinath, R., Muthusamy, S., Krishnasamy, T. R., and Viloria, A. (2020). "Permeability properties of lightweight self-consolidating concrete made with coconut shell aggregate," Joural of Materials Research and Technology 9(3), 3547-3557. DOI: 10.1016/j.jmrt.2020.01.092

Palmqvist, E., Grage, H., Meinander, N. Q., and Hahn-Hagerdal, B. (1999). "Main and interaction effects of acetic acid, furfural, and phydroxybenzoic acid on growth and ethanol productivity of yeasts," Biotechnology and Bioengineering 63(1), 46-55. DOI: 10.1002/(SICI)1097-0290(19990405)63:13.3.CO;2-A

Rivas, B., Moldes, A. B., Domínguez, J. M., and Parajó, J. C. (2004). “Development of culture media containing spent yeast cells of Debaryomyces hansenii and corn steep liquor for lactic acid production with Lactobacillus rhamnosus," International Journal of Food Microbiology 97(1), 93-98. DOI: 10.1016/j.ijfoodmicro.2004.05.006

Ruan, C. S., Zhu, Y. J., Zhou, X., Abidi, N., Hu, Y., and Catchmark, M. J. (2016). "Effect of cellulose crystallinity on bacterial cellulose assembly," Cellulose 23, 3417-3427. DOI: $10.1007 / \mathrm{s} 10570-016-1065-0$

Santos, S. M., Carbajo, J. M., and Villa, J. C. (2013). "The effect of carbon and nitrogen sources on bacterial cellulose production and properties from Gluconacetobacter sucrofermentans CECT 7291 focused on its use in degraded paper restoration," BioResources 8(3), 3630-3645. DOI: 10.15376/biores.8.3.3630-3645

Segal, L., Creely, J. J., Martin, A. E., Jr., and Conrad, C. M. (1959). “An empirical method for estimating the degree of crystallinity of native cellulose using the X-ray diffractometer," Textile Research Journal 29, 786-794. DOI: $10.1177 / 004051755902901003$ 
Shoda, M., and Sugano, Y. (2005). "Recent advances in bacterial cellulose production," Biotechnology and Bioprocess Engineering 10, 1-8. DOI: 10.1007/bf02931175

Wang, Z., Huang, G. M., Zhao, B., Li, S. D., Lu, D. X., and Hu, D. (2017). "Extraction and structural characterization of hemicellulose from coconut coir fiber," Food Sciences 38, 245-249. DOI: 10.7506/spkx1002-6630-201714038 (in Chinese with English abstract)

Wang, X. H., Zhang, C. H., Lin, Q. X., Cheng, B. G., Kong, F. G., Li, H. L., and Ren, J. L. (2018). "Solid acid-induced hydrothermal treatment of bagasse for production of furfural and levulinic acid by a two-step process," Industrial Crops \& Products 123, 118-127. DOI: $10.1016 /$ j.indcrop.2018.06.064

Wang, J., Tavakoli, J., and Tang, Y. (2019). "Bacterial cellulose production, properties and applications with different culture methods - A review," Carbohydrate Polymers 219, 63-76. DOI: 10.1016/j.carbpol.2019.05.008

Xiang, Q., Kim, S. J., and Lee, Y. Y. (2003). "A comprehensive kinetic model for diluteacid hydrolysis of cellulose," Applied Biochemistry and Biotechnology 106(1-3), 337352. DOI: 10.1385/abab:106:1-3:337

Yang, X. Y., Huang, C., Guo, H. J., Xiong, L., Luo, J., Wang, B., Lin, X. Q., Chen, X. F., and Chen, X. D. (2014). "Bacterial cellulose production from the litchi extract by Gluconacetobacter xylinus," Preparative Biochemistry and Biotechnology 46(1), 3943. DOI: 10.1080/10826068.2014.958163

Ye, J., Zheng, S., Zhang, Z., Yang, F., Ma, K., Feng, Y., Zheng, J., Mao, D., and Yang, X. (2019). "Bacterial cellulose production by Acetobacter xylinum ATCC 23767 using tobacco waste extract as culture medium," Bioresource Technology 274, 518-524. DOI: 10.1016/j.biortech.2018.12.028

Zhang, Q. Y., Feng, X. J., Chen, X. D., and L, K. (2020). "Mix design for recycled aggregate pervious concrete based on response surface methodology," Construction and Building Materials 259, 119776. DOI: 10.1016/j.conbuildmat.2020.119776

Article submitted: August 28, 2020; Peer review completed: September 20, 2020; Revised version submitted: December 11, 2020; Published: December 17, 2020.

DOI: 10.15376/biores.16.1.1042-1062 


\section{APPENDIX}
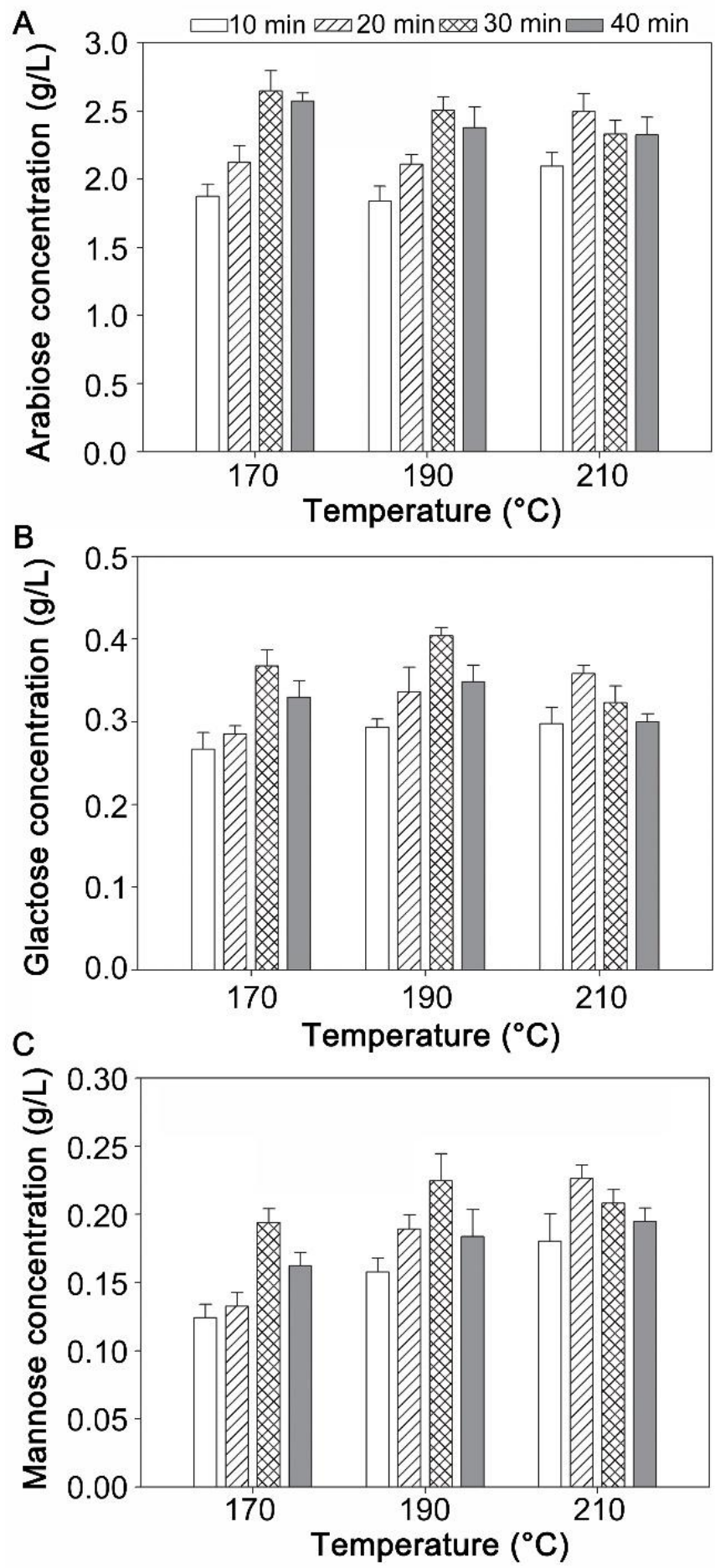

Fig. S1. Effect of time and temperature on concentrations of $(A)$ arabinose, $(B)$ galactose, and (C) mannose in coconut shell hydrolysis. Coconut shell was treated by sulfuric acid of $0.05 \%$ mass fraction for $10,20,30$, or 40 minutes at 170,190 , or $210^{\circ} \mathrm{C}$. Data are the means $\pm S D$ of three biological assays. 
Table S1. Concentrations of Fermentation Inhibitors in Detoxified Hydrolysate of Coconut Shell under Different Treatment Conditions at $\mathrm{pH} 6$

\begin{tabular}{lllllllll}
\hline $\begin{array}{l}\text { Activated carbon } \\
\text { dose }(\mathrm{g} / \mathrm{L})\end{array}$ & $\begin{array}{l}\text { Formic acid } \\
(\mathrm{g} / \mathrm{L})\end{array}$ & $\begin{array}{l}\text { Loss } \\
(\%)\end{array}$ & $\begin{array}{l}\text { Acetic acid } \\
(\mathrm{g} / \mathrm{L})\end{array}$ & $\begin{array}{l}\text { Loss } \\
(\%)\end{array}$ & $\begin{array}{l}\text { Furfural } \\
(\mathrm{g} / \mathrm{L})\end{array}$ & $\begin{array}{l}\text { Loss } \\
(\%)\end{array}$ & $\begin{array}{l}5-\mathrm{HMF}^{\mathrm{a}} \\
(\mathrm{g} / \mathrm{L})\end{array}$ & $\begin{array}{l}\text { Loss } \\
(\%)\end{array}$ \\
\hline 0 & $1.44 \pm 0.05$ & 0 & $0.72 \pm 0.04$ & 0 & $0.31 \pm 0.02$ & 0 & $0.17 \pm 0.01$ & 0 \\
1 & $1.34 \pm 0.06$ & 6.83 & $0.66 \pm 0.02$ & 8.47 & $0.26 \pm 0.01$ & 16.35 & $0.10 \pm 0.01$ & 40.57 \\
2 & $1.26 \pm 0.03$ & 12.39 & $0.54 \pm 0.02$ & 24.67 & $0.19 \pm 0.01$ & 37.94 & $0.06 \pm 0.01$ & 64.92 \\
3 & $1.15 \pm 0.04$ & 18.42 & $0.54 \pm 0.02$ & 25.58 & $0.10 \pm 0.01$ & 67.51 & - & $\approx 100$ \\
4 & $1.09 \pm 0.03$ & 24.18 & $0.48 \pm 0.03$ & 31.87 & - & $\approx 100$ & - & $\approx 100$ \\
\hline
\end{tabular}

5-HMFa: 5-hydroxymethylfurfural

Table S2. Concentrations of Fermentation Inhibitors in Detoxified Hydrolysate of Coconut Shell under Different Treatment Conditions at $\mathrm{pH} 7$

\begin{tabular}{lllllllll}
\hline $\begin{array}{l}\text { Activated carbon } \\
\text { dose }(\mathrm{g} / \mathrm{L})\end{array}$ & $\begin{array}{l}\text { Formic acid } \\
(\mathrm{g} / \mathrm{L})\end{array}$ & $\begin{array}{l}\text { Loss } \\
(\%)\end{array}$ & $\begin{array}{l}\text { Acetic acid } \\
(\mathrm{g} / \mathrm{L})\end{array}$ & $\begin{array}{l}\text { Loss } \\
(\%)\end{array}$ & $\begin{array}{l}\text { Furfural } \\
(\mathrm{g} / \mathrm{L})\end{array}$ & $\begin{array}{l}\text { Loss } \\
(\%)\end{array}$ & $\begin{array}{l}5-\mathrm{HMF}^{\mathrm{a}} \\
(\mathrm{g} / \mathrm{L})\end{array}$ & $\begin{array}{l}\text { Loss } \\
(\%)\end{array}$ \\
\hline 0 & $1.44 \pm 0.04$ & 0 & $0.72 \pm 0.04$ & 0 & $0.31 \pm 0.02$ & 0 & $0.17 \pm 0.01$ & 0 \\
1 & $1.38 \pm 0.05$ & 4.27 & $0.66 \pm 0.02$ & 7.94 & $0.25 \pm 0.01$ & 18.57 & $0.12 \pm 0.01$ & 27.85 \\
2 & $1.30 \pm 0.03$ & 9.68 & $0.60 \pm 0.02$ & 15.57 & $0.14 \pm 0.01$ & 53.69 & $0.12 \pm 0.01$ & 29.51 \\
3 & $1.21 \pm 0.05$ & 15.79 & $0.54 \pm 0.02$ & 25.04 & $0.10 \pm 0.01$ & 68.12 & - & $\approx 100$ \\
4 & $1.16 \pm 0.03$ & 18.79 & $0.53 \pm 0.03$ & 26.68 & - & $\approx 100$ & - & $\approx 100$ \\
\hline
\end{tabular}

5-HMFa: 5-hydroxymethylfurfural 